\title{
Release of exosomes from differentiated neurons and its regulation by synaptic glutamatergic activity.
}

Gaelle Lachenal $^{1,3}$, Karin Pernet-Gallay ${ }^{2,3}$, Mathilde Chivet ${ }^{1,3}$, Fiona J. Hemming ${ }^{1,3}$, Agnès Belly ${ }^{1,3}$, Gilles Bodon ${ }^{1,3}$, Béatrice Blot ${ }^{1,3}$, Georg Haase ${ }^{4}$, Yves Goldberg ${ }^{1,3}$ and Rémy Sadoul ${ }^{1,3}$.

1 INSERM, U836, Equipe 2, Neurodégénérescence et Plasticité, Grenoble, F38042,

France

2 INSERM, U836, Equipe 1, Physiopathologie du Cytosquelette, Grenoble, F38042,

France

3 Université Joseph Fourier, Grenoble Institut des Neurosciences, Grenoble, F38042, France

4 CNRS \& Université de la Méditerranée, UMR 6196, Plasticité et Physio-Pathologie de la Motricité, F-13402 Marseille cedex 20, France

Corresponding author : Rémy Sadoul, Grenoble Institute of Neuroscience,

Chemin Fortuné Ferrini, BP 170, F- 38042 Grenoble, France. remy.sadoul@ujf-grenoble.fr. Tel: +33 456520544 Fax: +33 456520554

Abbreviations used: DIV: days in vitro; EM: Electron microscopy; GFP: green fluorescent protein; HRP: horse radish peroxydase; MVB: Multivesicular body; TTC: C-terminal half of the tetanus toxin heavy chain; 


\begin{abstract}
Exosomes are microvesicles released into the extracellular medium upon fusion to the plasma membrane of endosomal intermediates called multivesicular bodies. They represent ways for discarding proteins and metabolites and also for intercellular transfer of proteins and RNAs. In the nervous system, it has been hypothesized that exosomes might be involved in the normal physiology of the synapse and possibly allow the trans-synaptic propagation of pathogenic proteins throughout the tissue. As a first step to validate this concept, we used biochemical and morphological approaches to demonstrate that mature cortical neurons in culture do indeed secrete exosomes. Using electron microscopy, we observed exosomes being released from somato-dendritic compartments. The endosomal origin of exosomes was demonstrated by showing that the $\mathrm{C}$-terminal domain of tetanus toxin specifically endocytosed by neurons and accumulating inside multivesicular bodies, is released in the extracellular medium in association with exosomes. Finally, we found that exosomal release is modulated by glutamatergic synaptic activity, suggesting that this process might be part of normal synaptic physiology. Thus, our study paves the way towards the demonstration that exosomes take part in the physiology of the normal and pathological nervous system.
\end{abstract}

Key words: exosomes, multivesicular bodies, tetanus toxin, synaptic activity. 


\section{Introduction}

Cell to cell communication can occur through exchange of membrane vesicles. Some are generated inside endosomes and released upon fusion to the plasma membrane of endosomal intermediates called multivesicular bodies (MVBs) (Pan et al., 1985). In this latter case, the released intralumenal vesicles are referred to as exosomes. Since their original discovery in reticulocytes, exosomes were found to be secreted by an increasing number of cells and could be isolated from most body fluids including cerebral spinal fluid (Vella et al., 2008a). However, in most cases their physiological relevance has been difficult to show due to a lack of information on their biogenesis, origin and regulation.

MVB intraluminal vesicles contain proteins meant for degradation, which occurs upon fusion of the limiting membrane of MVBs with lysosomes (Futter et al., 1996). Until a decade ago, their release as exosomes was mainly regarded as a way of eliminating membrane material from cells, or cell compartments, lacking lysosomes. Exosomes also represent an alternative pathway for secretion of soluble proteins lacking signal sequences, or of membrane proteins (Qu et al., 2007; Zhang et al., 2006). Other functions deal with intercellular communication, as in the case of naïve dendritic cells, which become immuno-competent after binding and endocytosis of exosomes secreted by other activated dendritic cells. (Morelli et al., 2004; Thery et al., 2002). Exosomes released by mast cells were reported to contain RNAs including microRNAs and mRNAs, which modulate protein expression of receiving cells (Skog et al., 2008; Valadi et al., 2007). Thus, exosomes represent a way of transferring material between cells, allowing emitting cells to modify protein expression of receiving cells.

Exosomes have been proposed to be a novel way for intercellular communication contributing to the normal physiology of the nervous system and to the trans-synaptic transmission of pathogenic proteins (Fevrier et al., 2005; Smalheiser, 2007; Vella et al., 2008b). In line with this, several reports have described release of exosomes by cultured astrocytes (Taylor et al., 2007), microglial cells (Potolicchio et al., 2005), oligodendrocytes (Krämer-Albers et al., 2007) and developping neurons (Faure et al., 2006). However there has been no definite proof that mature neurons can secrete exosomes or that this process is regulated by neuronal activity. Here we demonstrate that i) fully differentiated cortical and hippocampal neurons in culture do indeed 
secrete vesicles having the biochemical and morphological features of exosomes, ii) these vesicles do correspond to intralumenal vesicles of MVBs since they contain on their surface TTC, the C-terminal domain of tetanus-toxin, which is endocytosed by neurons and accumulates inside MVBs and iii) exosomal secretion by neurons is regulated by calcium influx and by glutamatergic synaptic activity. Thus our results definitively endorse the role of exosomes in the normal physiology of the central nervous system. 


\section{Material and Methods}

Reagents:

Polyclonal anti-Alix has been previously described (Chatellard-Causse et al., 2002). Polyclonal anti-L1 CAM was a kind gift of F. Rathjen (Max-Delbrück-Centrum, Berlin, Germany). Polyclonal anti-GluR2 and anti-GluR2/3 were purchased from Millipore and Chemicon respectively. Monoclonal antibody against the $\mathrm{N}$-terminal part of GluR2 used for electron microscopy was from Chemicon. Monoclonal antiGFP was from Covance, and monoclonal antibody against flotillin-1 was obtained from BD Transduction Laboratories.

Ionomycine, picrotoxin, CNQX, MK801 were purchased from Sigma and bicucullin from Fluka.

TTC proteins: construction of pGEX plasmids coding for GST-GFP-TTC or GSTGFP have been described in (Bordet et al., 2001). Proteins were expressed in BL21 E. coli and purified on a glutathion-Sepharose $4 \mathrm{~b}$ column (Amersham) as described (Bordet et al., 2001). After dialysis against PBS containing $0.5 \mathrm{M} \mathrm{NaCl}$ and $5 \%$ glycerol, proteins were centrifuged at $100000 \mathrm{~g}$ for $1 \mathrm{~h}$ to remove insoluble proteins. Fusion proteins were incubated on neurons at $4 \mu \mathrm{g} / \mathrm{ml}$ in culture medium.

\section{Primary cultures of cortical and hippocampal neurons:}

Cells were prepared from embryonic day 19 (E19) rat embryos as described (Fauré et al, 2006). After dissociation cortical neurons were seeded at $10^{5}$ cells $/ \mathrm{cm}^{2}$ onto 100 $\mathrm{mm}$ dishes precoated with poly-D-lysine (50 $\mu \mathrm{g} / \mathrm{ml}$, Sigma). Hippocampal neurons, cells were seeded at $1.3 \times 10^{4}$ cells $/ \mathrm{cm}^{2}$. Cells were cultured in Neurobasal (Gibco) supplemented with 2\% B27 (Gibco), $1 \mathrm{mM}$ sodium pyruvate, $2 \mathrm{mM}$ glutamine and antibiotics in a humidified incubator at $37^{\circ} \mathrm{C}$ and $5 \% \mathrm{CO}_{2} .25 \%$ freshly made medium containing cytosine $\beta$-D-arabinoside (AraC) at a final concentration of $10 \mu \mathrm{M}$ (cortical neurons) or $5 \mu \mathrm{M}$ (hippocampal neurons) was added every $4^{\text {th }}$ day. Immunostaining of 15 DIV cultures with a monoclonal antibody against GFAP, revealed staining of only 1 to $2 \%$ of cells, demonstrating minimal contamination by astrocytes.

\section{Purification of exosomes:}


Exosomes were purified from 15 DIV cortical neurons or from 21 DIV hippocampal neurons. Cells were washed two times in $\mathrm{K} 5$ medium $\left(5 \mathrm{mM} \mathrm{KCl}, 1.8 \mathrm{mM} \mathrm{CaCl}_{2}, 0.8\right.$ $\mathrm{mM} \mathrm{MgSO}_{4}, 110 \mathrm{mM} \mathrm{NaCl}, 26 \mathrm{mM} \mathrm{NaHCO}_{3}, 1 \mathrm{mM} \mathrm{NaH}_{2} \mathrm{PO}_{4}, 0.7 \%$ D-glucose and $15 \mathrm{mM}$ HEPES, pH 7.4). Cells were then incubated in the same medium, with or without stimulation, for the indicated times of harvest, after which media were collected and cleared of debris by two successive centrifugation steps (2 $000 \mathrm{~g}$ for 10 $\mathrm{min}, 20000 \mathrm{~g}$ for $20 \mathrm{~min}$ ) and filtration through a $0.22 \mu \mathrm{m}$ filter (GVA, Millipore). Exosomes were recovered by centrifugation for $50 \mathrm{~min}$ at $100000 \mathrm{~g}$. They were resuspended in Laemmli buffer for Western blot analysis or further separated over a sucrose gradient. For this, the $100000 \mathrm{~g}$ pellets were resuspended in sucrose $0.211 \mathrm{M}$, $3 \mathrm{mM}$ imidazole $\mathrm{pH} 7.4$, and loaded onto a continuous $0.211 \mathrm{M}$ to $2.255 \mathrm{M}$ sucrose gradient. Gradients were centrifuged $18 \mathrm{~h}$ at $100000 \mathrm{~g}$, and one $\mathrm{ml}$ fractions were collected, diluted in $3 \mathrm{mM}$ Imidazole, $\mathrm{pH} 7.4$, and centrifuged for $1 \mathrm{~h}$ at $100000 \mathrm{~g}$. Pellets were resuspended in Laemmli buffer and analysed by Western-blot.

For short term harvests each lane corresponds to exosomes pelleted at $100000 \mathrm{~g}$ from the medium of $1.2 \times 10^{7}$ cells (estimated at the time of seeding). Gradient analyses were performed using vesicles recovered from media of $3.6 \times 10^{7}$ cells.

Cells were lysed in RIPA buffer and the equivalent of $6 \times 10^{3}$ cells/ lane were loaded. Treatments included: depolarisation by incubation in $\mathrm{K} 25(25 \mathrm{mM} \mathrm{KCl}, 1.8 \mathrm{mM}$ $\mathrm{CaCl}_{2}, 0.8 \mathrm{mM} \mathrm{MgSO} 4,90 \mathrm{mM} \mathrm{NaCl}, 26 \mathrm{mM} \mathrm{NaHCO}_{3}, 1 \mathrm{mM} \mathrm{NaH} \mathrm{PO}_{4}, 0.7 \%$ Dglucose and $15 \mathrm{mM}$ HEPES, pH 7.4). All other treatments were performed for the times indicated in K5 medium: ionomycin was used at $2 \mu \mathrm{M}$, BAPTA-AM at $50 \mu \mathrm{M}$, bicucullin and picrotoxin at $40 \mu \mathrm{M}, \mathrm{MK} 801$ at $1 \mu \mathrm{M}$ and CNQX at $100 \mu \mathrm{M}$.

\section{Semi-quantificative analysis of Western blots:}

Autoradiographs were scanned (Duoscan f40, AGFA) at 800dpi. Total grey values were obtained using Metamorph software (Meta Imaging Series Version 7.5.6.0, MDS Analytical Technologies). For each experiment, triplicates were made from at least three different cultures. Histograms represent the means of ratios between each grey value of one exosomal pellet to the corresponding lysate.

\section{Electron microscopy:}

Exosome pellets were immediately fixed by $2 \%$ paraformaldehyde, applied to formvar-carbon-coated EM grids and stained with 5\% uranyl acetate for $1 \mathrm{~min}$. For 
immunogold labelling, grids were incubated with primary antibodies as indicated, which were then revealed using protein A gold. The exosomes were then stained with uranyl acetate as described above.

For morphological analysis, cultures of cortical or hippocampal neurons were stimulated for $1 \mathrm{~min}$ with $2 \mu \mathrm{M}$ ionomycin. Neurons were then fixed immediately in $2.5 \%$ glutaraldehyde in cacodylate buffer $0.1 \mathrm{M} \mathrm{pH} 7.2$, for at least $2 \mathrm{~h}$. Neurons were post-fixed by $1 \%$ osmium tetroxyde in cacodylate buffer $0.1 \mathrm{M}$ for $1 \mathrm{~h}$, stained overnight in $0.5 \%$ uranyl acetate, washed and dehydrated in a graded series of ethanol before inclusion in Epoxy resine (Fluka, Sigma). Ultrathin sections of $70 \mathrm{~nm}$ were cut with an ultramicrotome (Leica, ultracut S) and stained with uranyl acetate 5\% and lead citrate.

For immunogold labelling, cells were incubated overnight with GFP-TTC, washed three times in $\mathrm{K} 5$ medium, incubated with $2 \mu \mathrm{M}$ ionomycin for $1 \mathrm{~min}$ and fixed with $2 \%$ paraformaldehyde. Cells were then incubated with anti-GFP antibodies and protein A coupled to gold particles before inclusion as described above.

For cryomicroscopy, GFP-TTC was incorporated as described above and the cells fixed with $2 \%$ paraformaldehyde, $0.2 \%$ glutaraldehyde in cacodylate buffer $0.1 \mathrm{M}$. Cells were scratched off the substrate and centrifuged at $1200 \mathrm{rpm}$ for $5 \mathrm{~min}$. Pellets were then embedded in gelatine, cryo-protected in 2.3 M sucrose and frozen in liquid nitrogen. Sections of $70 \mathrm{~nm}$ were cut using a cryo-ultramicrotome (Reichert Ultracut $\mathrm{S}$, Leica) and immunolabelling was performed according to Tokuyasu (Tokuyasu, 1986). Observations were made using a transmission electron microscope (JEOL JEM $1200 \mathrm{EX}$ ) at $80 \mathrm{kV}$, equipped with a digital camera (Veleta, SIS). 


\section{Results}

Exosomal release from mature neurons is regulated by calcium.

Exosomes are homogeneous in size $(40-100 \mathrm{~nm})$ and shape and even though their protein composition depends on the cell type of origin, some proteins like Alix or flotillin-1 have emerged as exosomal marker proteins (Mathivanan and Simpson, 2009). We have previously demonstrated that primary neurons from E 19 rat cortex cultured for 9 days release exosomes and that this release is stimulated during prolonged depolarisation $(3 \mathrm{~h}$ ) with medium containing $25 \mathrm{mM} \mathrm{KCl}$ (Faure et al., 2006). These cultures are not fully differentiated, meaning that neurite outgrowth still occurs and that very few synapses can be observed. In order to show that exosomal release is not only a property of developing neurons, we used here cortical neurons cultured for 15 days to allow full differentiation (Chiappalone et al., 2006). After washing, the cultures were incubated in harvesting medium containing $5 \mathrm{mM} \mathrm{KCl}$ (K5) or in the same medium containing $25 \mathrm{mM} \mathrm{KCl} \mathrm{(K25).} \mathrm{Media} \mathrm{were} \mathrm{harvested}$ after $3 \mathrm{~h}$, vesicles pelleted by ultracentrifugation and further separated using a continuous sucrose gradient. As shown in Fig. 1, immunoblotting of each fraction using an antibody against flotillin-1 revealed weak immunoreactivity in fraction 5 from K5 cell-supernatants and strong reactivity peaking between fractions 4 and 7 from K25 supernatants. This corresponds to densities of 1.09 and $1.15 \mathrm{~g} / \mathrm{ml}$ sucrose, as expected for exosomes (Fig. 1). Alix was mainly detected in fractions 4 to 6 of K25 supernatants. The cell adhesion molecule L1, a transmembrane protein, which in the central nervous system is only expressed by neurons (Maness and Schachner, 2007), was present in exosomal fractions of the same supernatants showing that exosomes are released by neurons. Immunoreactivity against GluR2/3 showed that subunits of AMPA receptors are also secreted by way of exosomes. These results demonstrate that mature neurons secrete exosomes and that this process is enhanced by depolarisation.

In order to examine whether this secretion can be regulated, we next used a harvesting time of $5 \mathrm{~min}$ to avoid long term effects of treatments on endosomal trafficking. Using $100000 \mathrm{~g}$ centrifugation, we found that harvested media contained pelletable material positive for Alix, flotillin-1 and L1 (Fig. 2). In this case the amount of material was too small to allow separation over sucrose gradients; we therefore used electron microscopy to demonstrate that the $100000 \mathrm{~g}$ pellets contained exosomes. Indeed, released vesicles harvested after $5 \mathrm{~min}$ had the size $(50-100 \mathrm{~nm})$ and 
erythrocyte-like shape typical of exosomes. (Fig. 2D). The neuronal origin of these vesicles was demonstrated by their labelling with antibodies against L1 and the AMPA receptor subunit GluR2 (Fig. 2D, bottom panel).

Using a 5 min harvest, we found that incubation of neurons with the calcium inonophore ionomycin to induce calcium influx, significantly increased exosomal release (Fig. 2A and B). Similar results were found using 21 DIV hippocampal neurons (Fig. 2C). Preincubation of cortical neurons for 15 min with BAPTA-AM, to chelate intracellular calcium, partially blocked the ionomycin effect, thus demonstrating that the enhancement of exosomal release observed during a $5 \mathrm{~min}$ incubation with the ionophore is indeed due to an increase in intracellular calcium (Fig. 2E and F).

Electron-microscopic examination of cultured neurons reveals the presence of released exosomes in close apposition to the plasma membrane.

Electron microscopic examination of 15 DIV cortical neurons treated 1 min with ionomycin showed the presence of extracellular clusters of vesicles in close vicinity of the plasma membrane of dendrites (Fig. 3B right panel) and of the soma (Fig. 3B left panel). Similar clusters were seen, albeit less frequently, on the surface of untreated 15 DIV (not shown) or 8 DIV cultures (Fig. 3A). The size (40 to $80 \mathrm{~nm}$ ) was compatible to the one of vesicles harvested from culture supernatants (Fig. 2D). Moreover the size and number of vesicles were also in the same range as those observed inside MVBs (Fig. 3A and B). In rare cases, profiles of MVB compartments in continuity with the plasma membrane could be observed (Fig. 3C). Dense material probably contained in MVBs was released together with exosomes.

GFP-TTC is released by way of exosomes.

In order to further prove that exosomes harvested by centrifugation and observed in association with the plasma membrane originate in neuronal endosomal compartments, we made use of TTC, the $\mathrm{C}$ terminal 451-amino-acid fragment of the Tetanus toxin heavy chain. Numerous observations have shown that the recombinant protein fused to GFP or enzymes, binds specifically to- and is endocytosed by neurons similarly to the native toxin (Bordet et al., 2001)(Francis et al., 2004). Here we produced GFP-tagged TTC (GFP-TTC) and GFP as recombinant GST fusion proteins in bacteria. Cortical neurons cultured for $15 \mathrm{DIV}$ were then incubated for $1 \mathrm{~h}$ at $37^{\circ} \mathrm{C}$ with GFP-TTC or GFP before extensive washing. Using epi-fluorescence, endocytosed GFP-TTC was 
seen inside punctuate structures in both soma and dendrites, whereas GFP alone was undetectable (not shown). To test whether GFP-TTC is secreted in association with exosomes, neurons pre-incubated with GFP-TTC or GFP, were extensively washed and incubated in fresh medium. The media were harvested after $5 \mathrm{~min}$., exosomes centrifuged at $100000 \mathrm{~g}$ and analysed by Western-blotting using anti-GFP and antiflotillin-1 antibodies. GFP-TTC, but not GFP, was present in these $100000 \mathrm{~g}$ pellets (Fig. 4A). The amount of released GFP-TTC pelleted by ultracentrifugation was significantly increased upon treatment of neurons with $2 \mu \mathrm{M}$ ionomycin further suggesting that GFP-TTC is released in association with exosomes (Fig. 4C). We next used density separation to further prove that after endocytosis by neurons, GFP-TTC is secreted in association with exosomes. Neurons were preincubated with GFP-TTC, extensively washed and vesicles harvested during $2 \mathrm{~h}$ were further separated on a sucrose gradient. Western blotting analysis using antibodies against GFP revealed a peak of GFP-TTC in the $1.12 \mathrm{~g} / \mathrm{ml}$ fraction, in which flotillin positive exosomes are concentrated (Fig. 4B). As expected from the result shown in Fig. 4A, no GFP could be detected in any fractions of exosomes prepared from neurons which had been preincubated with GFP alone (not shown). The most straight-forward explanation as to why GFP-TTC is detected at this sucrose density is that it is bound to exosomes. These data prove that exosomes secreted by neurons stem from intracellular compartments, which contain endocytosed proteins.

In order to demonstrate that these endosomes are indeed MVBs, we used immunogold to label cryosections of cultured neurons pre-incubated with GFP-TTC. As shown in Fig. 4D, some of the anti-GFP labelling was found inside MVB compartments which is in good agreement with data from Schiavo and collaborators using recombinant TTC coupled to horse radish peroxydase (Deinhardt et al., 2006).

Anti-GFP labelling before inclusion and sectioning of the cultured neurons preincubated with GFP-TTC, demonstrated the presence of immunogold labelling on exosomes present in extracellular clusters at the neuron surface (Fig. 4E). Thus, our experiments strongly suggest that the packets of exosomes seen in association with dendrites of 15 DIV cultured neurons correspond to intralumenal vesicles of MVBs released upon fusion of the latter with the plasma membrane.

Exosome secretion is regulated by glutamatergic activity 
We finally tested whether secretion of exosomes might be regulated by synaptic activity. For this we used two antagonists of $\mathrm{GABA}_{\mathrm{A}}$ receptors, bicucullin or picrotoxin, to block inhibitory activity in the cultures and thereby enhance glutamatergic spontaneous activity. As shown in Fig. 5A and B, massive increase in release of exosomes detected by flotillin-1, Alix and L1 was detectable after a 10 min treatment with bicucullin. Antibodies against the $\mathrm{Na}+\mathrm{K}+$ ATPase, a plasma membrane resident protein, did not reveal the presence of the protein in the same fractions, thus demonstrating that the vesicles harvested from neurons treated with or without bicucullin do not contain plasma membrane contaminants (not shown). Addition of the AMPAR antagonist CNQX to the cultures together with bicucullin inhibited this increase, demonstrating that secretion is modulated by synaptic AMPA receptor activity. MK-801, which antagonises NMDA receptors also blocked the bicucullin induced increase in exosome secretion (Fig. 5A and B). Therefore exosome secretion is modulated by synaptic AMPA- and NMDA-receptors. Picrotoxin also increased the release of exosomes immuno-revealed using anti-flotillin and GluR2 further demonstrating that this process is regulated by glutamatergic activity (Fig. 5C). 


\section{Discussion}

Vesicles released from living cells are the subject of numerous studies as they represent ways of secreting cytoplasmic proteins, membrane proteins and RNAs (Belting and Wittrup, 2008). Secretion of membrane particles was demonstrated to occur directly from the plasma membrane of neuroepithelial cells (Marzesco et al., 2005), microglia (Bianco et al., 2005), astrocytes (Bianco et al., 2009) or glioblastoma cells (Skog et al., 2008). Vesicles can also be released from intracellular compartments of unknown origin as in the case of enlargeosomes released by PC12 cells (Borgonovo et al., 2002). The best-characterised membrane vesicles are exosomes, which correspond to intralumenal vesicles of MVBs released after fusion of the latter to the plasma membrane (Simons and Raposo, 2009). Exosomes represent a way of intercellular exchange of both RNAs and proteins, which allows emitting cells to modify protein expression in receiving cells. In the adult nervous system exosomes were hypothesized to supplement the known mechanisms of anterograde and retrograde signalling across synapses i.e. represent a novel way for intercellular exchange of material within neural networks (Smalheiser, 2007) (Aguzzi and Rajendran, 2009; Vella et al., 2008b). Even appealing this hypothesis faces the lack of demonstration of exosomal release by mature neurons. Among the reports claiming secretion of exosomes by neurons (Ghidoni et al., 2009; Putz et al., 2008; Vingtdeux et al., 2007), only Ghidoni et al. (2009) separated by density centrifugation exosomes from other vesicles harvested from culture supernatants. None of the reports used markers to ensure the neuronal origin of the secreted vesicles. Furthermore, no demonstration was made of the endosomal origin of the putative exosomes. Finally all these reports used embryonic neurons cultured for only 3 to 7 days; our previous demonstration of exosome release by neurons made use of embryonic cortical neurons cultured for 8 to 9 days (Faure et al., 2006). In such cultures, neurite outgrowth is still ongoing and exosomal release might simply reflect the fusion of late endosomeslysosomes at growth cones, a process necessary for neurite elongation (Arantes and Andrews, 2006). Here we used several appoaches to show that cortical neurons cultured for 15 days, which have undergone synaptogenis and made functional networks (Chiappalone et al., 2006) release exosomes. We also show that exosomal release is regulated by synaptic glutamatergic activity and might thus be part of normal synaptic physiology. 
Our demonstration that the features of vesicles released by differentiated neurons correspond to those of exosomes is five fold: 1) their floating between 1.09 and 1.15 $\mathrm{g} / \mathrm{ml}$ of sucrose; 2) their characteristic Alix and flotillin- immunoreactivities; 3) their size and shape as observed by electron microscopy; 4) their association with the Cterminal half of tetanus toxin which is endocytosed specifically by neurons and accumulates inside MVBs; 5) the presence of clusters of vesicles near dendrites, which have the size and shape similar to those found inside MVBs and are labelled with GFP- TTC.

As in the case for exosomes secreted from 8 DIV cultures (Faure et al., 2006), exosomes released by 15 DIV neurons carried the cell adhesion molecule L1 and GluR2/3 subunits of AMPA receptors. The presence of both proteins inside MVBs, which was reported by others (Utvik et al., 2009; Yap et al., 2008), is compatible with our conclusion that exosomes characterised in our study indeed correspond to MVB intralumenal vesicles of neurons. We verified that this is indeed the case by making use of GFP-TTC. In primary cultures, this protein is specifically endocytosed by neurons, a property afforded by TTC which binds to cell surface gangliosides and a GPI-linked receptor (Bordet et al., 2001; Herreros et al., 2001). In agreement with published results, we observed by EM that the endocytosed protein accumulates inside neuronal MVBs. Enrichment of GFP-TTC in sucrose fractions containing exosomes harvested from neurons having endocytosed GFP-TTC demonstrated that the water soluble protein is bound to exosomes. The protein was also detected by EM on exosomes present in extracellular clusters close to the neuronal surface. Altogether these findings demonstrate that endocytosed GFP-TTC is secreted by way of exosomes and that neuronal exosomes characterised throughout our study stem from MVBs.

Thus, our finding that 15 DIV mature cortical neurons secrete exosomes at the level of soma and dendritic shafts was crucial to demonstrate that this process might be part of the physiology of differentiated neuron and is unrelated to growth cone development.

Even if several cell stimuli lead to an increase in exosome secretion by non neuronal cells (Thery et al., 2009), there is today no clear indication that MVB fusion is regulated. In most cell types, a rise in cytosolic calcium is necessary to induce regulated secretion (Gerber and Sudhof, 2002). The lack of information about a possible calcium dependent fusion of MVBs to the plasma membrane is due to the 
length of exosome harvest necessary to detect exosomes (ranging from several hours to several days) (see for example (Fader et al., 2008; Ostrowski et al., 2010; Savina et al., 2005). Such a long-term rise in calcium could be misleading in that it affects endosomal traffic and potentially the number of MVBs without regulating secretion per se. The best evidence, so far, for a role of calcium in exosomal release was given by $\mathrm{Qu}$ et al., who reported, a slight increase in exosomal release by macrophages during a 15 min ATP stimulation (Qu et al., 2009). Here we managed to show a strong increase in exosomal release from mature neurons within 5 min of ionomycin treatment, that is abolished by BAPTA-AM. Using EM we also found that the number of extracellular clusters near neuronal surfaces is increased upon 1 min treatment with ionomycin. Even if this is to our knowledge, the best suggestion so far that calcium regulates fusion of MVBs to the plasma membrane, the definite proof will await real time video microscopy to study this process.

By analogy to other cells, one might consider exosomes as a way of discarding proteins. In the cortex and hippocampus, regulation of the number of ionotropic glutamate receptors expressed at the post-synaptic membrane is crucial to modulate efficacy of synapses. It is now well documented that this regulation involves calcium regulated endocytosis and exocytosis from endosomal pools of receptors but little is known about how degradation contributes to this equilibrium (Kennedy and Ehlers, 2006; Newpher and Ehlers, 2008). The presence of GluR2 subunits in neuronal exosomes together with the enhanced secretion of exosomes following glutamatergic synaptic activation, underlines exosomal release as a possible mechanism for the local elimination of receptors at synapses undergoing plastic changes. The loss of AMPA receptors upon extensive synaptic activation could be a mechanism of homeostatic synaptic scaling, which is necessary to adjust the strength of all of a neuron's excitatory synapses to stabilize firing \{Turrigiano, 2008 \#5243\}. As distal dendrites are devoid of lysosomes, regulation of the pool of surface synaptic receptors by exosome secretion would avoid retrograde transport of MVBs to lysosomes in proximal dendrites and soma. In vivo, MVBs are relatively sparse and mostly found within dendritic shafts but rarely inside spines (Cooney et al., 2002). However, movements or maturation of MVBs in spines is tightly regulated by synaptic activity or neurotrophic factors (Popov et al., 2008; Rind et al., 2005). One important step will now be to test whether fusion of MVBs to the plasma membrane occurs at the level of spines or of dendritic shafts. 
Exosomes released by mast cells and dendritic cells where shown to be captured by other cells which can make use of the exosomal proteins and RNAs (Morelli et al., 2004; Thery et al., 2002). If such mechanisms allow material transfer between neurons they would be ideally suited to regulate protein expression and thereby plasticity inside neuronal networks (Smalheiser, 2007). In line with this, a recent report, Korkut et al. demonstrated a vesicular trans-synaptic communication of Wnt at the Drosophila neuromuscular junction and suggested that this occurs through exosome transfer (Korkut et al., 2009). Exosomal transfer would also allow the spreading of pathogenic agents throughout the central nervous system during the course of neurodegenerative diseases (Aguzzi and Rajendran, 2009; Vella et al., 2008b). The fact that TTC is secreted by way of exosomes adds some weight to this hypothesis since in vivo the recombinant protein behaves like intact Tetanus toxin, being endocytosed at synapses, retrogradely transported inside endosomes and crossing synapses (Cordero-Erausquin et al., 2009; Maskos et al., 2002)(Deinhardt et al., 2006). Our present work showing that differentiated neurons secrete exosomes stemming from MVBs in a way regulated by synaptic activity is a first step towards the demonstration of their function in the normal and pathological nervous system. 


\section{Legends to Figures}

Figure 1: Western blot analysis of secreted vesicles separated on a continuous density gradient.

After washing, 15 DIV cortical neurons were incubated in fresh K5 medium or depolarising medium containing $25 \mathrm{mM} \mathrm{KCl} \mathrm{(K25).} 3 \mathrm{~h}$ later, vesicles harvested from $3.6 \times 10^{7}$ cells were pelleted at $100000 \mathrm{~g}$. The vesicles were then separated on a continuous sucrose gradient. One $\mathrm{ml}$ fractions were collected and analysed by Western blot using antibodies against L1, GluR2/3, Alix and Flotillin-1. (TCL: Total cell lysates; Inp: 10\% of the vesicles pelleted at $100000 \mathrm{~g}$ before separation on the sucrose gradient.)

Figure 2: Exosomal secretion is regulated by calcium.

\section{A.,B.,C.: increase of exosomal release by ionomycin}

A. Cortical neurons (15 DIV) were incubated for $5 \mathrm{~min}$ in fresh medium (Ctrl,) or in fresh medium containing $2 \mu \mathrm{M}$ ionomycin. Exosomes released during these $5 \mathrm{~min}$ incubations were pelleted at $100000 \mathrm{~g}$ and analysed by Western-blot using the indicated antibodies (Crtl: control medium; Iono: ionomycin; TCL: Total cell lysates) B. L1, Flotillin-1 and Alix immuno-reactivities as shown in A were quantified by densitometry (Wilcoxon test, $*: 0.01<\mathrm{p}<0.05, * * 0.001<\mathrm{p}<0.01$ ).

C. Hippocampal neurons (21 DIV) were incubated for $5 \mathrm{~min}$ in fresh medium (Ctrl) or in fresh medium containing $2 \mu \mathrm{M}$ ionomycin (Iono). Exosomes released during these $5 \mathrm{~min}$ incubations were pelleted at $100000 \mathrm{~g}$ and analysed by Western-blot using the indicated antibodies. (TCL: Total cell lysate)

D. Characterisation of exosomes released during $5 \mathrm{~min}$.

Electron microscopy examination of vesicles secreted by 15 DIV cortical neurons during 5 min and pelleted at 100000 g. (bar: 100nm).

Bottom panels: Immunogold labelling of the same preparation using antibodies against L1 CAM (left) and GluR2 (right).

\section{E. BAPTA-AM inhibits the increase of exosomal release due to ionomycin.}

Cortical neurons were preincubated for $15 \mathrm{~min}$ in medium with or without $50 \mu \mathrm{M}$ BAPTA-AM. Neurons were then washed and incubated in fresh medium containing 2 
$\mu \mathrm{M}$ ionomycin during the $5 \mathrm{~min}$ harvest. Exosomes were pelleted at $100000 \mathrm{~g}$ and analysed by Western blots using the antibodies indicated.

F. L1, flotillin-1 and Alix immunoreactivities as shown in E were quantified using densitometry. (Wilcoxon test, $*: 0.01<\mathrm{p}<0.05, * *: 0.001<\mathrm{p}<0.001$

Figure 3. Clusters of exosomes are released by cortical neurons in culture.

A. Electron microscopy of cortical neurons (8 DIV) in culture shows extracellular clusters of vesicles having the size and shape of MVB intraluminal vesicles, which are loosely associated with the plasma membrane.

B. The same kind of figures can be seen on soma and dendrites of cortical neurons at 15 DIV, washed and incubated $1 \mathrm{~min}$ in fresh medium containing $2 \mathrm{mM}$ ionomycin before fixation.

C: Figures of exocytosis, which could represent fusion of MVBs with the plasma membrane. Bar: $200 \mathrm{~nm}$ for A,B,C

Figure 4. GFP-TTC is secreted in association with neuronal exosomes.

A. Cortical neurons were incubated at $37^{\circ} \mathrm{C}$ with GFP-TTC or GFP $(4 \mu \mathrm{g} / \mathrm{ml})$, before extensive washing. Exosomes secreted for $5 \mathrm{~min}$ were pelleted by $100000 \mathrm{~g}$ centrifugation (100 $000 \mathrm{~g}$ pellet) and analysed by Western blot using anti-GFP and anti-flotillin-1 antibodies. (TCL: Total cell lysates).

B. Cortical neurons (15 DIV) were incubated with GFP-TTC, extensively washed and depolarised by incubation with fresh medium containing $25 \mathrm{mM} \mathrm{KCl}$. After $2 \mathrm{~h}$, culture supernatants were harvested and vesicles pelleted at $100000 \mathrm{~g}$ (Inp). Vesicles were further separated on a sucrose density gradient. $1 \mathrm{ml}$ fractions were collected and analysed by Western blot using anti-GFP and anti-flotillin-1 antibodies.

C. Increased secretion of GFP-TTC bound exosomes induced by ionomycin: 15 DIV neurons were incubated $1 \mathrm{~h}$ at $37^{\circ} \mathrm{C}$ with GFP-TTC before extensive washing. Neurons were incubated with fresh medium containing $2 \mu \mathrm{M}$ ionomycin during the 5 min time of harvest. Exosomes were pelleted by $100000 \mathrm{~g}$ centrifugation and analysed by Western blot using anti-GFP and anti-flotillin-1 antibodies. (TCL: Total cell lysates). Right hand panel: Flotillin and GFP-TTC immunoreactivities were estimated using densitometry. (Wilcoxon test, *: $0.01<\mathrm{p}<0.05$ ) 
D. Cortical neurons (15 DIV) were pre-incubated with GFP-TTC, washed and processed for cryosections. GFP was detected using an anti-GFP and Protein A coupled to immunogold. (bars: $200 \mathrm{~nm}$ ).

E. Cortical neurons (15 DIV) pre-incubated with GFP-TTC as in A and B were fixed and labelled with GFP antibodies and Protein A coupled to gold beads before embedding. Sections were prepared and examined by EM. Arrows show GFP labelling on exosomes in clusters close to the plasma membrane. (bars: $200 \mathrm{~nm}$ ).

Figure 5. Exosomal release is regulated by glutamatergic synaptic activity.

A. Cortical neurons (15 DIV) were washed and incubated $10 \mathrm{~min}$ in fresh medium (Crtl) or the same medium containing $40 \mu \mathrm{M}$ bicucullin, in absence (0) or in presence of $1 \mu \mathrm{M} \mathrm{MK801} \mathrm{or} \mathrm{of} 100 \mu \mathrm{M}$ CNQX. Thereafter, media were collected and exosomes pelleted at $100000 \mathrm{~g}(100000 \mathrm{~g}$ pellet) and analysed by Western blot using the antibodies indicated. TCL: Total cell Lysate.

B. L1, Alix and flotillin immunoreactivities as shown in A were quantified (Anova test, $*: 0.01<\mathrm{p}<0.05, * * 0.001<\mathrm{p}<0.01)$.

C. Cortical neurons (15 DIV) were incubated in K5 medium containing $40 \mu \mathrm{M}$ picrotoxin. The incubation media were harvested after 10, 30 and $90 \mathrm{~min}$, exosomes pelleted at $100000 \mathrm{~g}$ and analysed by Western blot using the indicated antibodies. 
Acknowledgements:

This work was supported in part by INSERM, the Université Joseph Fourier, and grants from the Association Française contre les Myopathies, the Association pour la Recherche contre le Cancer and the Association France Alzheimer. G.L. was supported by a fellowship from the

Fondation pour la Recherche Médicale. A. B. was supported by the Association France Alzheimer

We thank K. Sadoul and A. Depaulis for critical reading of the manuscript, C. ChatellardCausse and T. Grömer for numerous suggestions throughout this work.

\section{References}

Aguzzi, A., Rajendran, L., 2009. The transcellular spread of cytosolic amyloids, prions, and prionoids. Neuron 64, 783-790.

Arantes, R.M., Andrews, N.W., 2006. A role for synaptotagmin VII-regulated exocytosis of lysosomes in neurite outgrowth from primary sympathetic neurons. $\mathrm{J}$ Neurosci 26, 4630-4637.

Belting, M., Wittrup, A., 2008. Nanotubes, exosomes, and nucleic acid-binding peptides provide novel mechanisms of intercellular communication in eukaryotic cells: implications in health and disease. J Cell Biol 183, 1187-1191.

Bianco, F., Perrotta, C., Novellino, L., Francolini, M., Riganti, L., Menna, E., Saglietti, L., Schuchman, E.H., Furlan, R., Clementi, E., Matteoli, M., Verderio, C., 2009. Acid sphingomyelinase activity triggers microparticle release from glial cells. Embo J 28, 1043-1054.

Bianco, F., Pravettoni, E., Colombo, A., Schenk, U., Moller, T., Matteoli, M., Verderio, C., 2005. Astrocyte-derived ATP induces vesicle shedding and IL-1 beta release from microglia. J Immunol 174, 7268-7277.

Bordet, T., Castelnau-Ptakhine, L., Fauchereau, F., Friocourt, G., Kahn, A., Haase, G., 2001. Neuronal targeting of cardiotrophin-1 by coupling with tetanus toxin $\mathrm{C}$ fragment. Mol Cell Neurosci 17, 842-854.

Borgonovo, B., Cocucci, E., Racchetti, G., Podini, P., Bachi, A., Meldolesi, J., 2002. Regulated exocytosis: a novel, widely expressed system. Nat Cell Biol 4, 955-962.

Chatellard-Causse, C., Blot, B., Cristina, N., Torch, S., Missotten, M., Sadoul, R., 2002. Alix (ALG-2-interacting protein X), a protein involved in apoptosis, binds to endophilins and induces cytoplasmic vacuolization. J Biol Chem 277, 2910829115.

Chiappalone, M., Bove, M., Vato, A., Tedesco, M., Martinoia, S., 2006. Dissociated cortical networks show spontaneously correlated activity patterns during in vitro development. Brain Res 1093, 41-53.

Cooney, J.R., Hurlburt, J.L., Selig, D.K., Harris, K.M., Fiala, J.C., 2002. Endosomal Compartments Serve Multiple Hippocampal Dendritic Spines from a Widespread Rather Than a Local Store of Recycling Membrane. J. Neurosci. 22, 2215-2224.

Cordero-Erausquin, M., Allard, S., Dolique, T., Bachand, K., Ribeiro-da-Silva, A., De Koninck, Y., 2009. Dorsal horn neurons presynaptic to lamina I spinoparabrachial neurons revealed by transynaptic labeling. J Comp Neurol 517, 601-615.

Deinhardt, K., Berninghausen, O., Willison, H.J., Hopkins, C.R., Schiavo, G., 2006. Tetanus toxin is internalized by a sequential clathrin-dependent mechanism initiated within lipid microdomains and independent of epsin1. J Cell Biol 174, 459-471. 
Fader, C.M., Sanchez, D., Furlan, M., Colombo, M.I., 2008. Induction of autophagy promotes fusion of multivesicular bodies with autophagic vacuoles in $\mathrm{k} 562$ cells. Traffic 9, 230-250.

Faure, J., Lachenal, G., Court, M., Hirrlinger, J., Chatellard-Causse, C., Blot, B., Grange, J., Schoehn, G., Goldberg, Y., Boyer, V., Kirchhoff, F., Raposo, G., Garin, J., Sadoul, R., 2006. Exosomes are released by cultured cortical neurones. Mol Cell Neurosci 31, 642-648.

Fevrier, B., Vilette, D., Laude, H., Raposo, G., 2005. Exosomes: a bubble ride for prions? Traffic 6, 10-17.

Francis, J.W., Bastia, E., Matthews, C.C., Parks, D.A., Schwarzschild, M.A., Brown, R.H., Jr., Fishman, P.S., 2004. Tetanus toxin fragment $\mathrm{C}$ as a vector to enhance delivery of proteins to the CNS. Brain Res 1011, 7-13.

Futter, C.E., Pearse, A., Hewlett, L.J., Hopkins, C.R., 1996. Multivesicular endosomes containing internalized EGF-EGF receptor complexes mature and then fuse directly with lysosomes. J Cell Biol 132, 1011-1023.

Gerber, S.H., Sudhof, T.C., 2002. Molecular determinants of regulated exocytosis. Diabetes 51 Suppl 1, S3-11.

Ghidoni, R., Paterlini, A., Albertini, V., Glionna, M., Monti, E., Schiaffonati, L., Benussi, L., Levy, E., Binetti, G., 2009. Cystatin C is released in association with exosomes: A new tool of neuronal communication which is unbalanced in Alzheimer's disease. Neurobiol Aging.

Grumelli, C., Verderio, C., Pozzi, D., Rossetto, O., Montecucco, C., Matteoli, M., 2005. Internalization and mechanism of action of clostridial toxins in neurons. Neurotoxicology 26, 761-767.

Herreros, J., Ng, T., Schiavo, G., 2001. Lipid rafts act as specialized domains for tetanus toxin binding and internalization into neurons. Mol Biol Cell 12, 29472960.

Kennedy, M.J., Ehlers, M.D., 2006. Organelles and trafficking machinery for postsynaptic plasticity. Annu Rev Neurosci 29, 325-362.

Korkut, C., Ataman, B., Ramachandran, P., Ashley, J., Barria, R., Gherbesi, N., Budnik, V., 2009. Trans-synaptic transmission of vesicular Wnt signals through Evi/Wntless. Cell 139, 393-404.

Krämer-Albers, E.M., Bretz, N., Tenzer, S., Winterstein, C., Möbius, W., Berger, H., Nave, K.A., Schild, H., Trotter, J., 2007. Oligodendrocutes secrete exosomes containing major myelin and stress-protective proteins: Trophic suppor for axons ? Proteomics Clin Appl. 1, 1446-1461.

Lalli, G., Bohnert, S., Deinhardt, K., Verastegui, C., Schiavo, G., 2003. The journey of tetanus and botulinum neurotoxins in neurons. Trends Microbiol 11, 431-437.

Maness, P.F., Schachner, M., 2007. Neural recognition molecules of the immunoglobulin superfamily: signaling transducers of axon guidance and neuronal migration. Nat Neurosci 10, 19-26.

Marzesco, A.M., Janich, P., Wilsch-Brauninger, M., Dubreuil, V., Langenfeld, K., Corbeil, D., Huttner, W.B., 2005. Release of extracellular membrane particles carrying the stem cell marker prominin-1 (CD133) from neural progenitors and other epithelial cells. J Cell Sci 118, 2849-2858.

Maskos, U., Kissa, K., St Cloment, C., Brulet, P., 2002. Retrograde trans-synaptic transfer of green fluorescent protein allows the genetic mapping of neuronal circuits in transgenic mice. Proc Natl Acad Sci U S A 99, 10120-10125.

Mathivanan, S., Simpson, R.J., 2009. ExoCarta: A compendium of exosomal proteins and RNA. Proteomics 9, 4997-5000. 
Miana-Mena, F.J., Roux, S., Benichou, J.C., Osta, R., Brulet, P., 2002. Neuronal activity-dependent membrane traffic at the neuromuscular junction. Proc Natl Acad Sci U S A 99, 3234-3239.

Morelli, A.E., Larregina, A.T., Shufesky, W.J., Sullivan, M.L., Stolz, D.B., Papworth, G.D., Zahorchak, A.F., Logar, A.J., Wang, Z., Watkins, S.C., Falo, L.D., Jr., Thomson, A.W., 2004. Endocytosis, intracellular sorting, and processing of exosomes by dendritic cells. Blood 104, 3257-3266.

Newpher, T.M., Ehlers, M.D., 2008. Glutamate receptor dynamics in dendritic microdomains. Neuron 58, 472-497.

Ostrowski, M., Carmo, N.B., Krumeich, S., Fanget, I., Raposo, G., Savina, A., Moita, C.F., Schauer, K., Hume, A.N., Freitas, R.P., Goud, B., Benaroch, P., Hacohen, N., Fukuda, M., Desnos, C., Seabra, M.C., Darchen, F., Amigorena, S., Moita, L.F., Thery, C., 2010. Rab27a and Rab27b control different steps of the exosome secretion pathway. Nat Cell Biol 12, 19-30; sup pp 11-13.

Pan, B.T., Teng, K., Wu, C., Adam, M., Johnstone, R.M., 1985. Electron microscopic evidence for externalization of the transferrin receptor in vesicular form in sheep reticulocytes. J Cell Biol 101, 942-948.

Popov, V.I., Medvedev, N.I., Kraev, I.V., Gabbott, P.L., Davies, H.A., Lynch, M., Cowley, T.R., Berezin, V., Bock, E., Stewart, M.G., 2008. A cell adhesion molecule mimetic, FGL peptide, induces alterations in synapse and dendritic spine structure in the dentate gyrus of aged rats: a three-dimensional ultrastructural study. Eur J Neurosci 27, 301-314.

Potolicchio, I., Carven, G.J., Xu, X., Stipp, C., Riese, R.J., Stern, L.J., Santambrogio, L., 2005. Proteomic analysis of microglia-derived exosomes: metabolic role of the aminopeptidase CD13 in neuropeptide catabolism. J Immunol 175, 2237-2243.

Putz, U., Howitt, J., Lackovic, J., Foot, N., Kumar, S., Silke, J., Tan, S.S., 2008. Nedd4 family-interacting protein 1 (Ndfip1) is required for the exosomal secretion of Nedd4 family proteins. J Biol Chem 283, 32621-32627.

Qu, Y., Franchi, L., Nunez, G., Dubyak, G.R., 2007. Nonclassical IL-1 beta secretion stimulated by $\mathrm{P} 2 \mathrm{X} 7$ receptors is dependent on inflammasome activation and correlated with exosome release in murine macrophages. J Immunol 179, 19131925.

Qu, Y., Ramachandra, L., Mohr, S., Franchi, L., Harding, C.V., Nunez, G., Dubyak, G.R., 2009. P2X7 receptor-stimulated secretion of MHC class II-containing exosomes requires the ASC/NLRP3 inflammasome but is independent of caspase1. J Immunol 182, 5052-5062.

Rind, H.B., Butowt, R., von Bartheld, C.S., 2005. Synaptic targeting of retrogradely transported trophic factors in motoneurons: comparison of glial cell line-derived neurotrophic factor, brain-derived neurotrophic factor, and cardiotrophin-1 with tetanus toxin. J Neurosci 25, 539-549.

Savina, A., Fader, C.M., Damiani, M.T., Colombo, M.I., 2005. Rab11 promotes docking and fusion of multivesicular bodies in a calcium-dependent manner. Traffic 6, 131-143.

Simons, M., Raposo, G., 2009. Exosomes - vesicular carriers for intercellular communication. Curr Opin Cell Biol 11, 11.

Skog, J., Wurdinger, T., van Rijn, S., Meijer, D.H., Gainche, L., Sena-Esteves, M., Curry, W.T., Jr., Carter, B.S., Krichevsky, A.M., Breakefield, X.O., 2008. Glioblastoma microvesicles transport RNA and proteins that promote tumour growth and provide diagnostic biomarkers. Nat Cell Biol 10, 1470-1476. 
Smalheiser, N.R., 2007. Exosomal transfer of proteins and RNAs at synapses in the nervous system. Biol Direct 2, 35.

Taylor, A.R., Robinson, M.B., Gifondorwa, D.J., Tytell, M., Milligan, C.E., 2007. Regulation of heat shock protein 70 release in astrocytes: role of signaling kinases. Dev Neurobiol 67, 1815-1829.

Thery, C., Duban, L., Segura, E., Veron, P., Lantz, O., Amigorena, S., 2002. Indirect activation of naive CD4 $+\mathrm{T}$ cells by dendritic cell-derived exosomes. Nat Immunol 3, 1156-1162.

Thery, C., Ostrowski, M., Segura, E., 2009. Membrane vesicles as conveyors of immune responses. Nat Rev Immunol 9, 581-593.

Tokuyasu, K.T., 1986. Application of cryoultramicrotomy to immunocytochemistry. J Microsc 143, 139-149.

Utvik, J.K., Haglerod, C., Mylonakou, M.N., Holen, T., Kropf, M., Hirling, H., Skare, O., Laake, P., Ottersen, O.P., Haug, F.M., Davanger, S., 2009. Neuronal enriched endosomal protein of $21 \mathrm{kDa}$ colocalizes with glutamate receptor subunit GLUR2/3 at the postsynaptic membrane. Neuroscience 158, 96-104.

Valadi, H., Ekstrom, K., Bossios, A., Sjostrand, M., Lee, J.J., Lotvall, J.O., 2007. Exosome-mediated transfer of mRNAs and microRNAs is a novel mechanism of genetic exchange between cells. Nat Cell Biol 9, 654-659.

Vella, L.J., Greenwood, D.L., Cappai, R., Scheerlinck, J.P., Hill, A.F., 2008a. Enrichment of prion protein in exosomes derived from ovine cerebral spinal fluid. Vet Immunol Immunopathol 124, 385-393.

Vella, L.J., Sharples, R.A., Nisbet, R.M., Cappai, R., Hill, A.F., 2008b. The role of exosomes in the processing of proteins associated with neurodegenerative diseases. Eur Biophys J 37, 323-332.

Vingtdeux, V., Hamdane, M., Loyens, A., Gele, P., Drobeck, H., Begard, S., Galas, M.C., Delacourte, A., Beauvillain, J.C., Buee, L., Sergeant, N., 2007. Alkalizing drugs induce accumulation of amyloid precursor protein by-products in luminal vesicles of multivesicular bodies. J Biol Chem 282, 18197-18205.

Yap, C.C., Wisco, D., Kujala, P., Lasiecka, Z.M., Cannon, J.T., Chang, M.C., Hirling, H., Klumperman, J., Winckler, B., 2008. The somatodendritic endosomal regulator NEEP21 facilitates axonal targeting of L1/NgCAM. J Cell Biol 180, 827-842.

Zhang, H.G., Liu, C., Su, K., Yu, S., Zhang, L., Zhang, S., Wang, J., Cao, X., Grizzle, W., Kimberly, R.P., 2006. A membrane form of TNF-alpha presented by exosomes delays T cell activation-induced cell death. J Immunol 176, 7385-7393. 
Figure 1

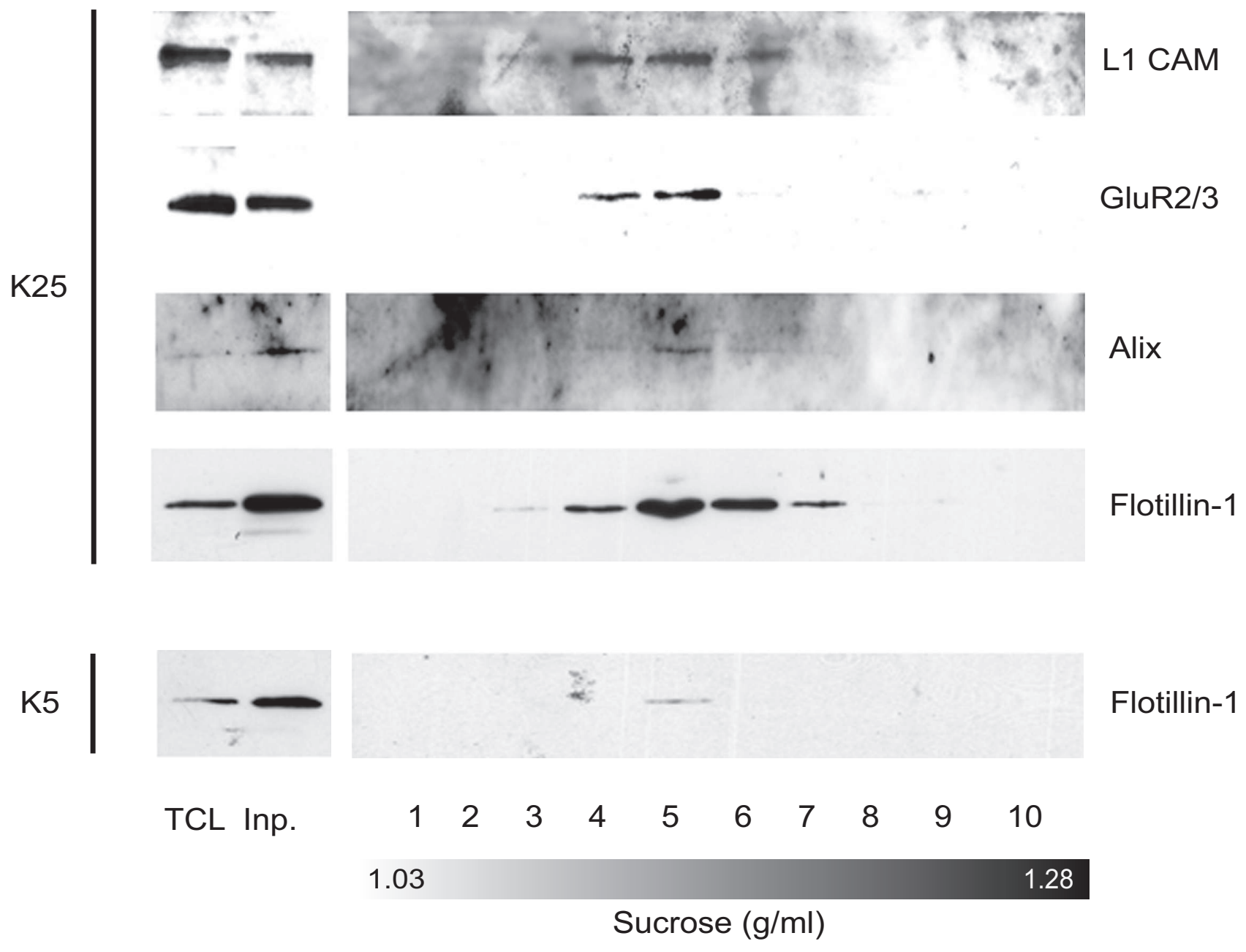


A.
$100000 \mathrm{~g}$ pellet
TCL
L1 CAM

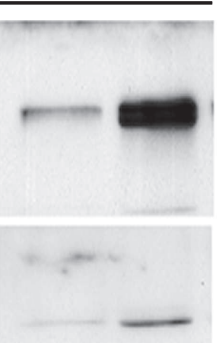
Alix

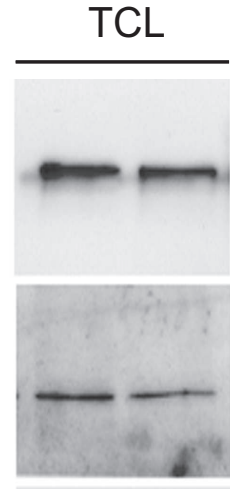
Flotillin-1
Ctrl Iono
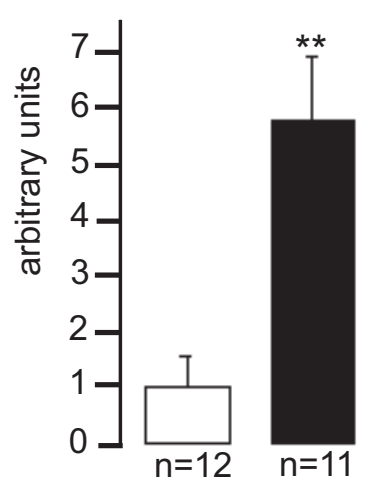
$\square$ Control
Ionomycin

C.

$100000 \mathrm{~g}$ pellet

TCL

Alix

$$
\text { x }
$$

Flotillin-1

\section{Ctrl Iono Ctrl Iono}

E.

$100000 \mathrm{~g}$ pellet

TCL
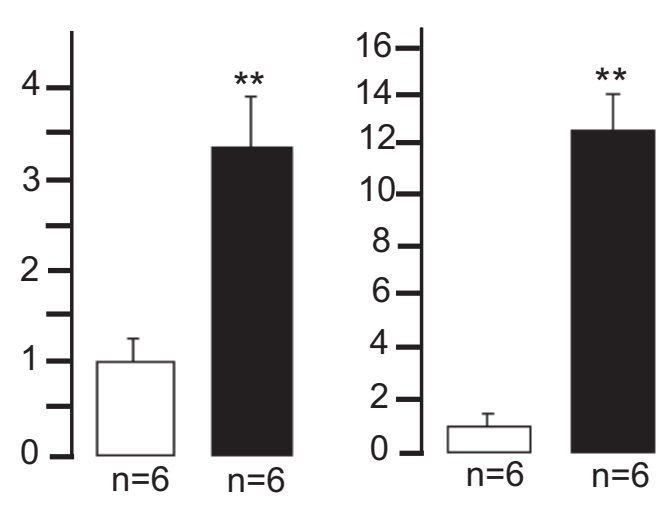

D.

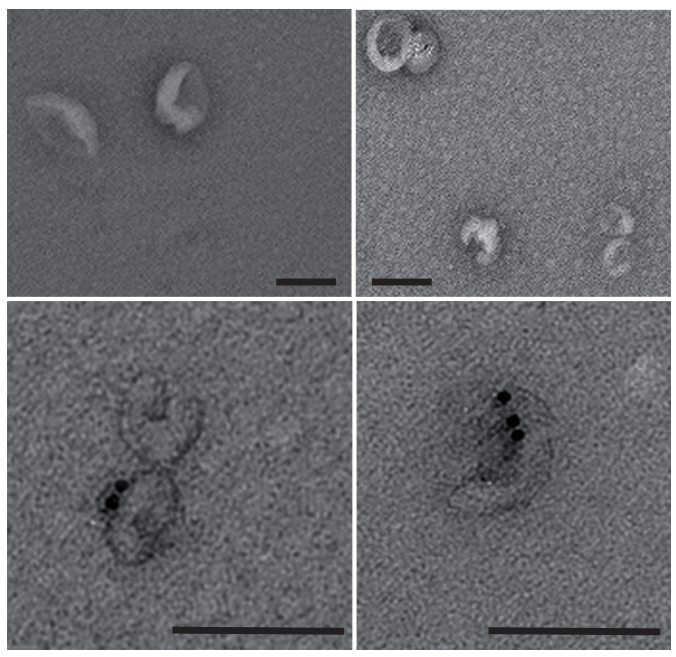

F.

L1 CAM

Flotillin-1

Alix
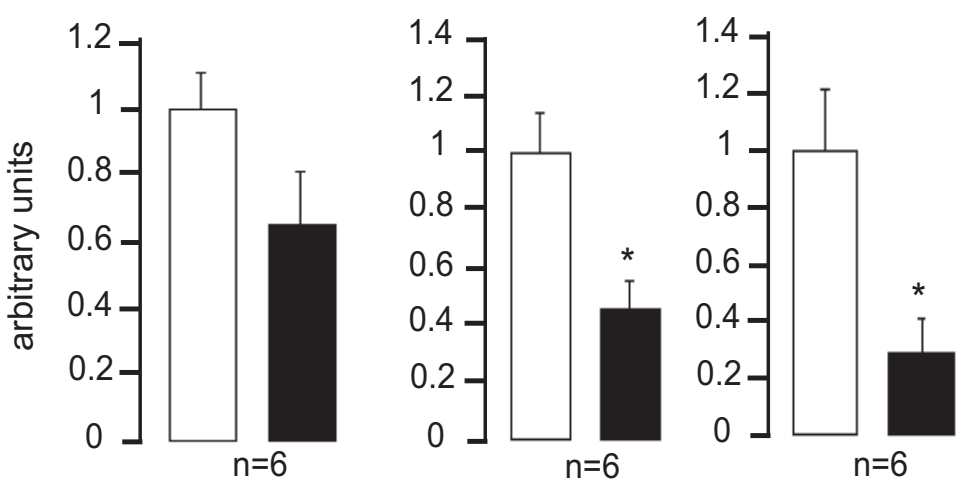

$\square$ lonomycin

lonomycin + BAPTA-AM
B.
Flotillin-1
Alix
L1 CAM

L1 CAM

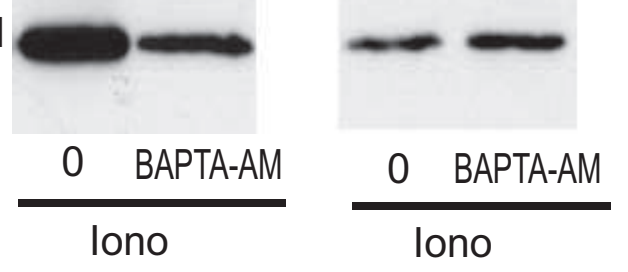

Flotillin-1
Alix
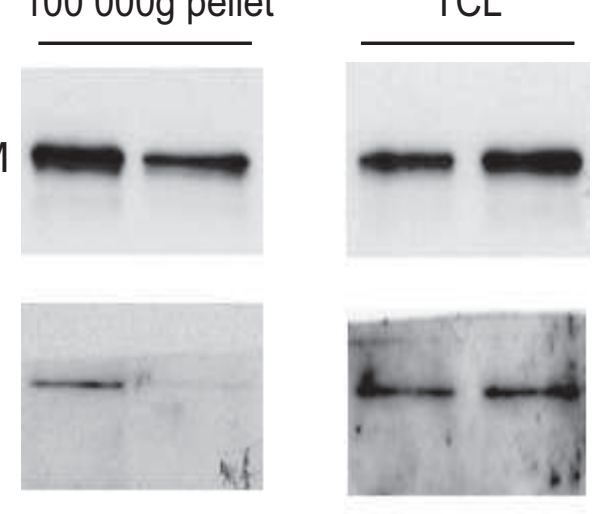

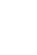




\section{Figure 3}

Click here to download Figure: Fig3.pdf

Figure 3

\section{A.}
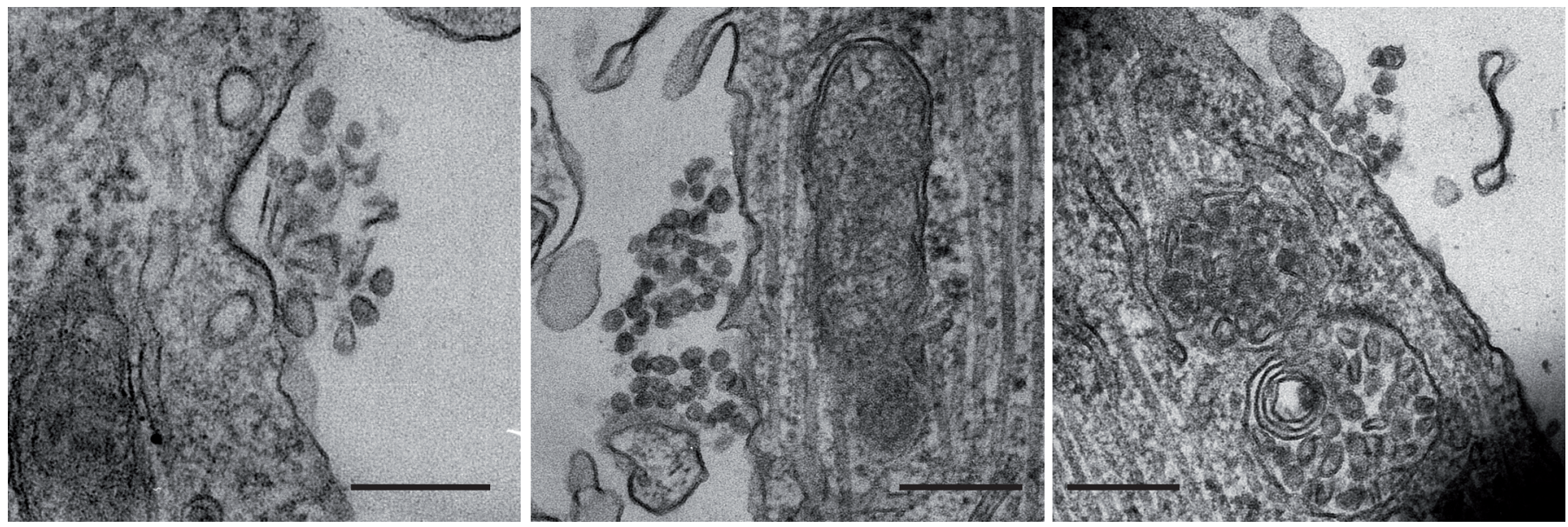

B.
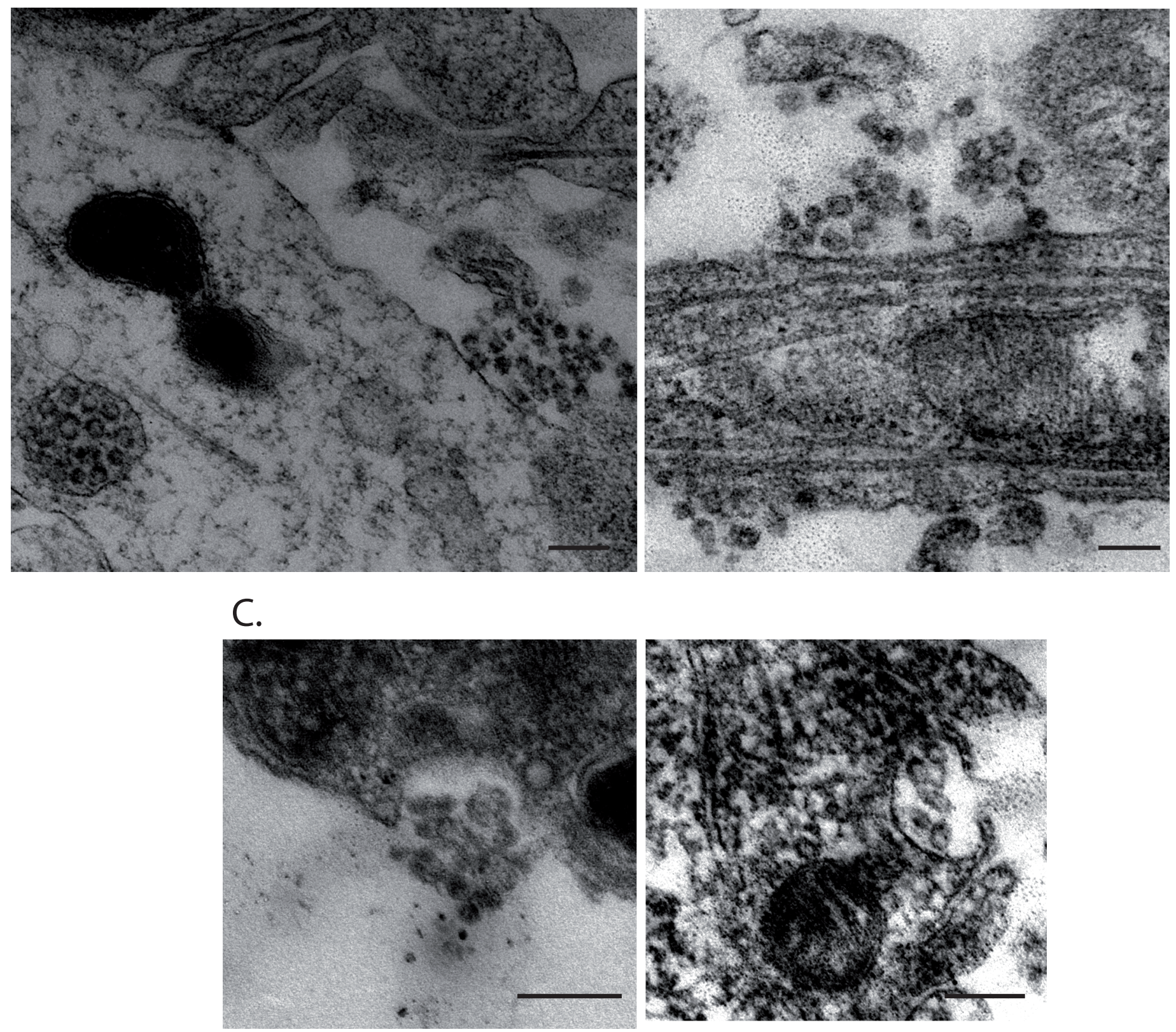
Figytequire 4

Clickhere to download Figure: Fig4 [Converti].pdf

A.

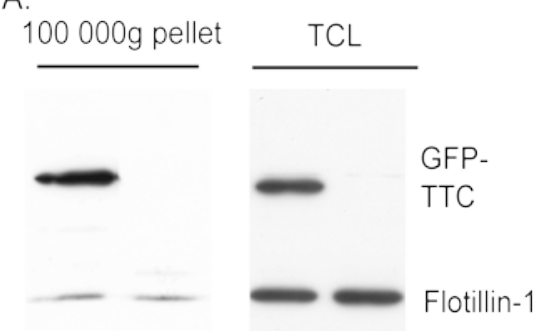

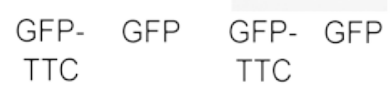

C.

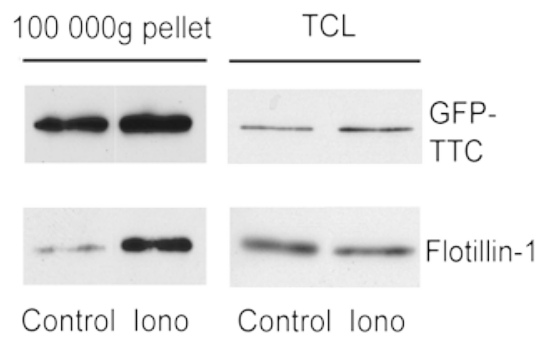

B.
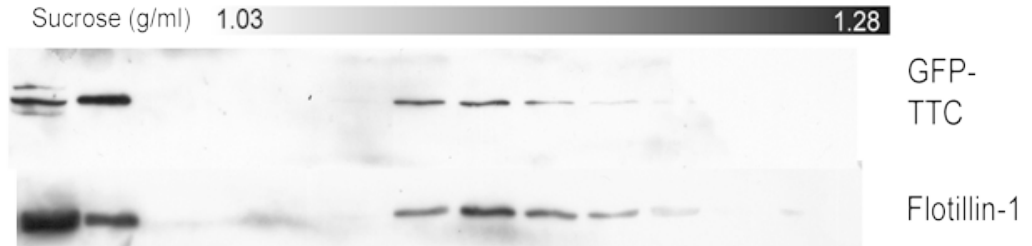

$\begin{array}{llllllllllll}\text { TCL Inp. } & 1 & 2 & 3 & 4 & 5 & 6 & 7 & 8 & 9 & 10 & 11\end{array}$

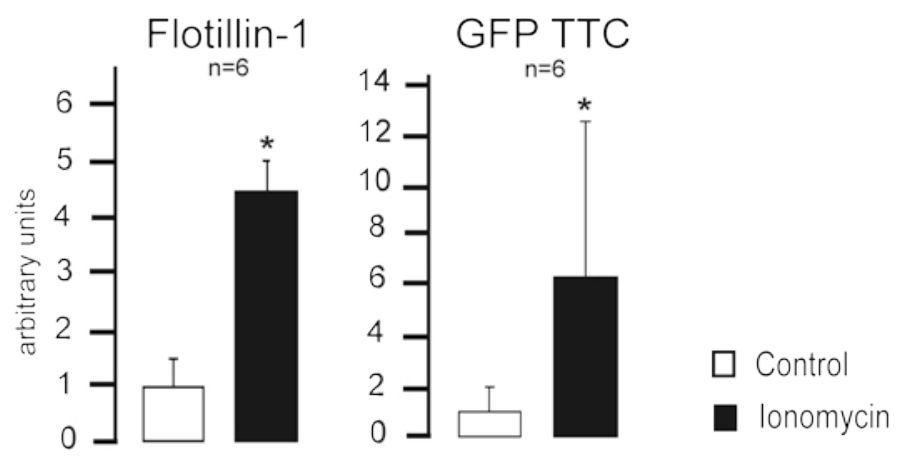

D.

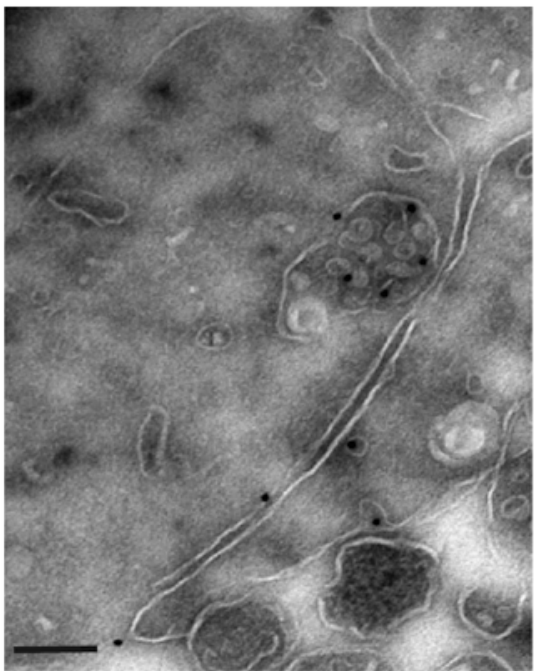

\section{E.}

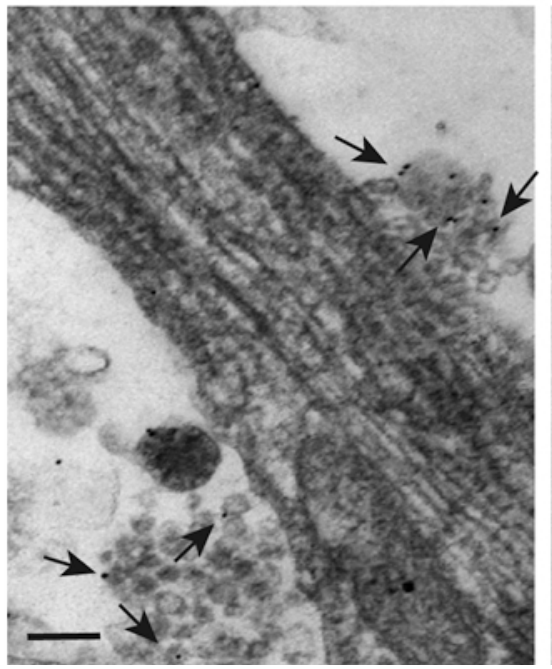

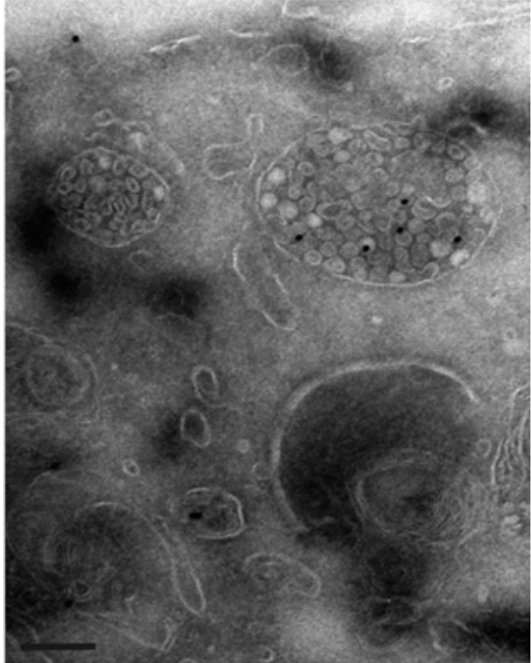

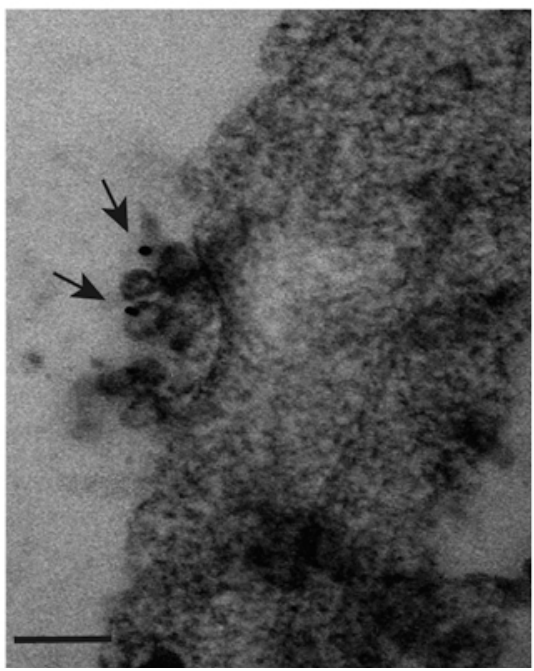


A. $100000 \mathrm{~g}$ pellet

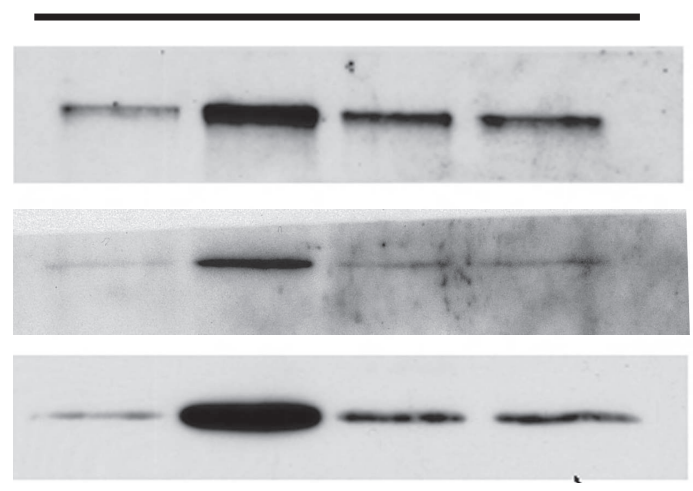

\begin{tabular}{llll} 
Ctrl & MK801 & CNQX \\
\hline
\end{tabular}

Bicucullin

B.

$\underset{n=3}{\operatorname{L}} \mathrm{CAM}$

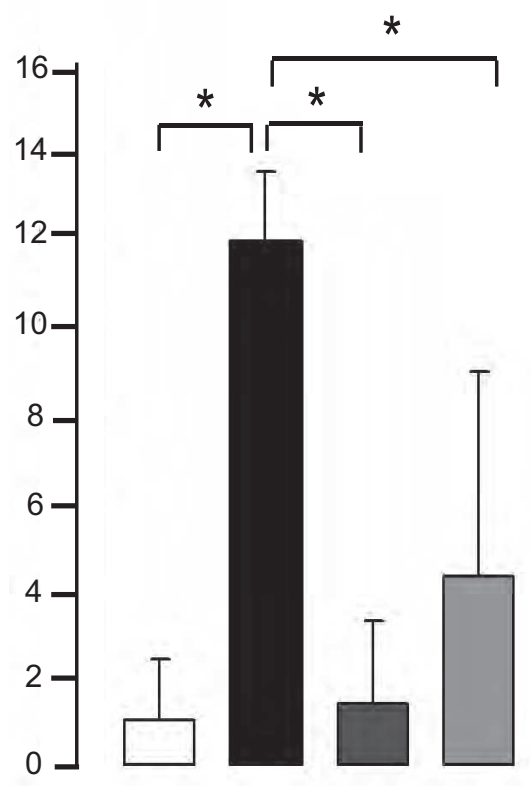

TCL

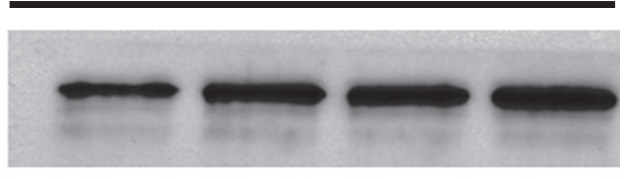

L1 CAM

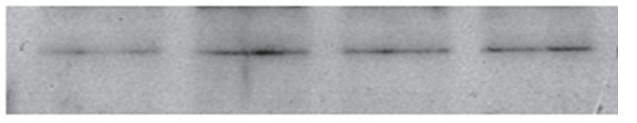

Alix

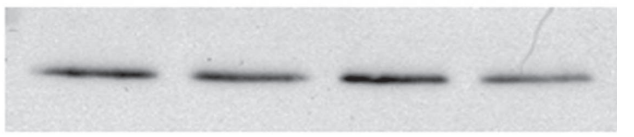

Flotillin-1

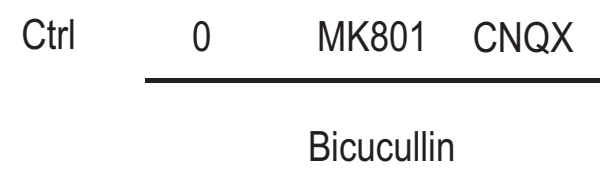

$\underset{n=3}{\operatorname{Alix}}$

Flotillin-1

$n=10$
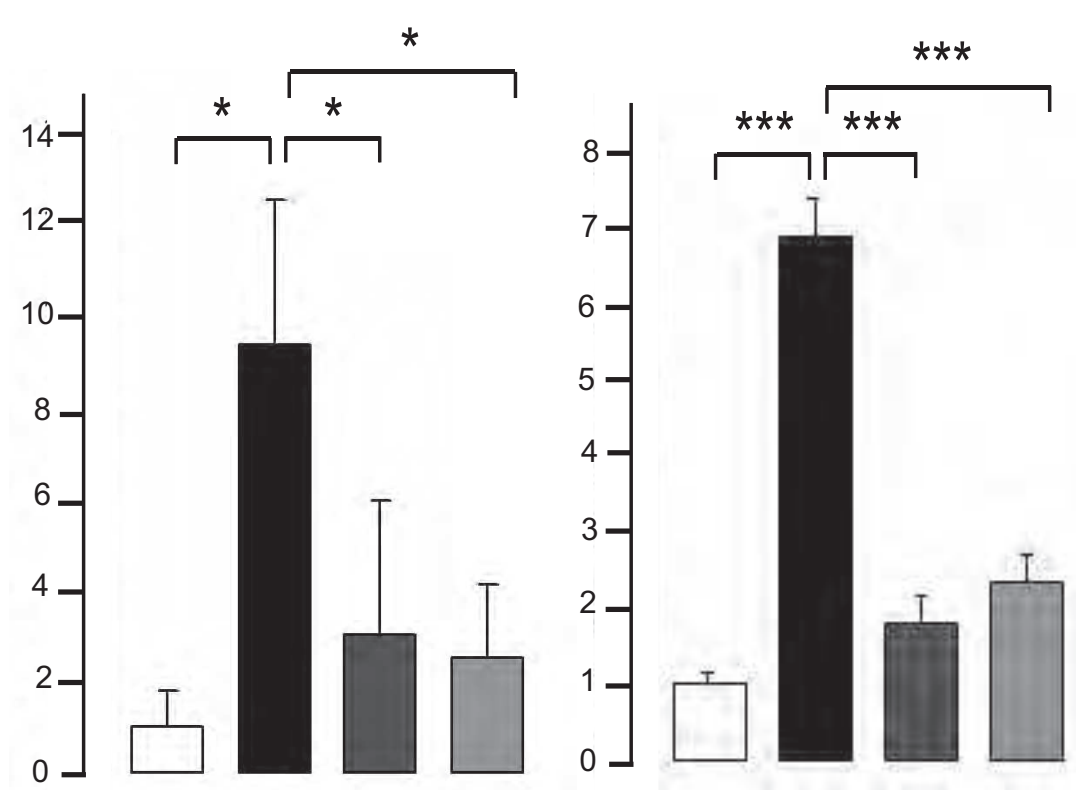

C.

$\square$ Control $\quad \square$ Bicucullin + MK801

Bicucullin $\square$ Bicucullin + CNQX

GluR2

Flotillin-1

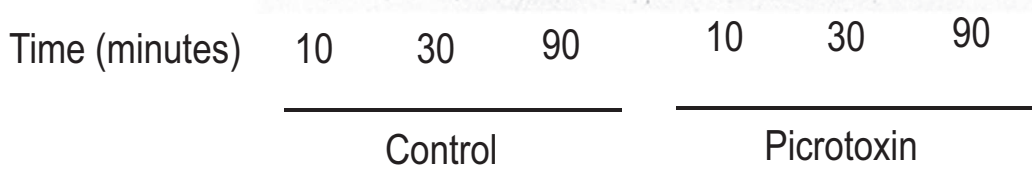

